\title{
Pitch temperatures in traditional farmhouse brewing
}

\author{
Lars Marius Garshol, Independent \\ larsga@garshol.priv.no
}

Paper submitted to Journal of the Institute of Brewing 2020-03-16. Not yet reviewed or accepted.

\begin{abstract}
Historically, farmhouse brewers brewed beer from their own grain all over northern Europe, using yeast they maintained in the local community. A large proportion of them, perhaps around $60 \%$, fermented at temperatures close to body temperature, according to a survey of 287 accounts of farmhouse brewing practices in 10 different countries. Recent genetic studies indicate that this was possible because the yeasts used in farmhouse brewing, although domesticated, were different from those used in modern brewing. Since wild yeast appears to have high temperature tolerance and modern commercial brewing arose out of earlier farmhouse brewing practices, it seems that the lack of high temperature tolerance in modern brewer's yeast may be due to a loss of function as the yeast adapted to commercial brewing practices.
\end{abstract}

\section{Introduction}

Historically, farmers across all of Europe brewed beer from their own grain. This practice seems to have roots all the way back to the Neolithic, but died out at different times in different countries. In southern Europe it was likely displaced by viticulture, while further north it was ended by legal obstacles, taxation, and modernisation in general (1).

However, in surprisingly large parts of northern Europe the same brewing tradition lives on even today, with brewing equipment and methods passed on from generation to generation. In some places, this includes the traditional yeast. Genetic studies have shown that the western Norwegian yeast strains, known as kveik, are domesticated, but belong to a separate lineage from modern brewing yeasts (2).

The traditional farmhouse yeasts stand out in many ways, and one of the most striking is the traditional pitch temperatures, which are extremely high by modern standards. For example, 
around the small town of Voss in western Norway, brewers generally pitch their yeast at 37 to 40 ${ }^{\circ} \mathrm{C}$.

This may sound unlikely, but repeated tests show that these yeasts produce clean, fresh-tasting beer despite the high temperatures. Fermentation can proceed at up to 42 , sometimes $43,{ }^{\circ} \mathrm{C}(2)$.

The high fermentation temperatures are not limited to western Norway, however. Intensive studies of farmhouse brewing documentation, much of it in archive sources, shows that these temperatures seem to have been the norm throughout northern Europe.

Several authors have already noted the prevalence of unusually warm temperatures in farmhouse brewing (for example references, see (2)). However, no attempt has been made at a systematic and comprehensive study, which is what this paper contributes.

The pitch temperatures of farmhouse brewers stand in stark contrast to those of modern commercial brewers. Lager brewers, of course, ferment very cold, but even ale brewers generally ferment in the range $15-20{ }^{\circ} \mathrm{C}$ and hardly ever go above $25{ }^{\circ} \mathrm{C} .{ }^{1}$ Economically, these brewers would benefit from fermenting warmer, since fermentation would then proceed faster, but this would cause off-flavours from the yeast (excessive ester formation, fusel alcohols, and so on), and so in practice this option is not open to brewers using modern yeast. ${ }^{2}$

\section{Materials and methods}

This paper examines what temperatures were common in traditional farmhouse brewing, to see if any trends can be made out in the material. To that end, it has been necessary to use specific types of sources that can be tabulated numerically. Therefore only first-hand descriptions of farmhouse brewing as it was practiced in a specific limited location have been included. A limited location here means a specific brewer, a specific village, or a specific county. Overview sources and more general accounts have been excluded from the survey.

\section{Sources}

Three types of material have been used:

${ }^{1}$ It is true that the Belgian saison brewers do go above $25^{\circ} \mathrm{C}$, but as these follow a tradition descending out of the local farmhouse brewing they confirm this pattern rather than contradict it.

2 Now, with the commercial availability of kveik yeast, strictly speaking the text should read "was not". 
- Published descriptions of brewing from local history societies, books, newspapers, trade magazines, ethnographical journals, and similar.

- Answers to ethnographic questionnaires. Ethnographic institutes in the Nordic and Baltic regions have sent out standardised surveys on a large number of subjects and collected the responses. Table 1 gives an overview of the material.

- Interviews with traditional brewers, and participating in brewing sessions with the brewers, all conducted by the author. When the brewers themselves don't know the correct temperature in numbers, but are able to recognise it, the author has measured the temperature once the brewers decide it is correct.

All told, this amounts to 1412 separate accounts, many of which provide no information at all on pitch temperatures. Of the ones that describe a pitch temperature, the description isn't always unambiguous or easy to interpret numerically. And the geographic distribution is necessarily uneven.

\section{Interpretation}

When an exact temperature is given, there is no problem. We assume this is the correct temperature. No doubt there will be occasional mistakes, where sources write the wrong number, misremember, or perhaps even simply make something up, but we assume the sheer number of sources will allow real trends to dominate.

If a single number is given, that number is used, and any verbal description of the temperature is ignored, even if it may appear to contradict the numeric temperature.

Sometimes the sources give a range, like $28-32{ }^{\circ} \mathrm{C}$, in which case we always pick the middle number. A range is difficult to work with, but the middle number is easy, unambiguous, and should not bias us in any direction. If a range is given we again ignore any verbal description.

In many of the older sources there is no exact number given, but instead a verbal description of how to recognise the correct temperature. In many cases these descriptions can be interpreted numerically.

One temperature that's often given is variations on the theme of body temperature. The actual descriptions may describe it as body temperature, or blood temperature, or the temperature of human skin. Since human body temperature is $37^{\circ} \mathrm{C}$, these accounts are recorded with that temperature. 
One may question whether brewers who use no thermometers can hit the correct temperature reliably. The author watched Dmitriy Zhezlov brew in Kirov oblast in Russia. He used no thermometer to find the pitch temperature, but said it should be "like the bathwater of a small child." In other words, body temperature. He measured it with his elbow, and when he was satisfied the author measured the temperature to $37{ }^{\circ} \mathrm{C}$ with a thermometer. So it does seem that these brewers can get very close to the desired temperature.

Another very common temperature is variations on the theme of "milkwarm." This was clearly a fixed expression in many different languages. Some refer to it as "teat warm". In a few cases the sources explain what they mean by the term: "as freshly milked milk" $(3,4)$, "as when the milk comes from the teat"(5), or "as the milk was when it ran straight into the bucket"(6). It clearly refers to the temperature of milk when it comes out of the cow. The body temperature of an adult cow is roughly $38.5^{\circ} \mathrm{C}$, so $35-38^{\circ} \mathrm{C}$ seems to be a reasonable assumption.

In the archive accounts, some specify both "milkwarm" and a temperature. The temperatures given are: 37, 35, 30 (here they say freshly sieved milk), 35, 35-37, 35, 30, 37, 22, 25-30. Four accounts say milkwarm is the same as body temperature. There thus seems to be a reasonable consensus in the sources that this temperature really is $35-37^{\circ} \mathrm{C}$. We therefore choose to use 36 ${ }^{\circ} \mathrm{C}$ for this temperature.

The sources also describe temperatures that are much harder to interpret.

Many say "lukewarm". The author's mother taught him that (at least in Norwegian) this effectively means body temperature, but there does not seem to be sufficient evidence to support that it's reliably used this way. These accounts are therefore excluded.

There are a number of accounts that say things along the lines of "if they could keep their hand in it", or their arm, or their elbow. Exactly what temperature this is, and how consistent it is, is hard to say. Marina Fyodorova in Chuvashia in Russia told the author that she had once tried this with a thermometer and found it to be $45^{\circ} \mathrm{C}$. Still, these temperatures are also excluded.

Then there is a whole range of variations on the theme of "when drops of tallow solidified on the surface". Unfortunately, tallow was historically made from both beef and mutton fat, and these two types of tallow congeal at different temperatures. Different sources indicate different temperatures for beef tallow: $30-38{ }^{\circ} \mathrm{C}$ and $40{ }^{\circ} \mathrm{C}$. The temperatures for mutton tallow are higher. None of the accounts give any indication which type of tallow they were using, which means that these accounts cannot be used.

(7) says the pitch temperature was milkwarm and that they felt this temperature with a finger. The source then goes on to say that some people let a drop of tallow fall into the wort, and when 
it congealed the temperature was right. This suggests that the milkwarm and tallow congealing temperatures are similar.

Some specify "summer hot" or "like summer water". These temperatures must be considerably colder, perhaps around $20^{\circ} \mathrm{C}$. They have also been excluded for being vague. There are only a few of these.

Some say one should feel "a cold ring around the arm" when dipping it in the wort. Again, this is too imprecise to use.

There is a risk that since the only non-numeric temperatures we recognise are around body temperature, we may be biasing the data set in favour of those temperatures. However, the "lukewarm", "can the arm stand it", and "tallow" temperatures are also probably in this range, and those are so many that they more than balance out the summer water and cold ring temperatures.

In any case, the uninterpretable accounts are so few (see table 2) that even if they are all considered to be $18 \mathrm{C}$ the overall conclusion remains the same.

\section{Results}

Collecting all 290 interpretable temperatures into a single histogram we get Figure 1. As can be seen, the range of temperatures is enormous: all the way from around 5 degrees up to 40 . The most striking feature is perhaps the giant peak at around body temperature.

Figure 2 shows clearly that pitch temperatures in the range $35-40{ }^{\circ} \mathrm{C}$ were the most common in Norway, Sweden, Denmark, and Estonia. Data for Lithuania, the UK, Russia, Germany, and Latvia is more sparse, but the picture there appears to be similar, except for Germany. In fact, more than half of all pitch temperatures are in the range $35-40{ }^{\circ} \mathrm{C}$.

A complicating factor is that farmhouse brewers use different types of yeast, which of course has different properties, and the pitch temperature is determined by what is appropriate for the yeast the brewers use. In general, traditional farmhouse brewers use three main types of yeast.

Every farmhouse brewing region originally had its own yeasts that were maintained by the brewers in that region. In this paper these yeasts are referred to as "farmhouse yeasts".

In regions where the farmhouse yeast has died out the farmhouse brewers have often switched to bread yeast and ferment with that. Very often they use the same pitch temperatures with bread yeast that they originally used for the farmhouse yeast. 
As can be seen in Figure 2 some Finnish brewers pitch at very low temperatures. These brewers are using the Finnish baking yeast Suomen Hiiva, and because this yeast can get out of hand, they pitch the yeast at very low temperatures, then let the wort temperature slowly rise to ambient temperature while the yeast gets started (8).

Some brewers have started buying modern commercial brewers yeast for their beer, and that yeast is pitched at the temperatures that are normal in modern brewing. Since the brewer is forced to pitch at a temperature that works for the yeast, there is no reason to assume that these were the same temperatures they pitched at when they had their own yeast. (In fact, as we'll see, it probably usually was not.)

For many accounts we have been able to distinguish between brewers that have their own yeast and those that do not, which means we can control for this factor. As can be seen in Figure 3 the dominance of the 35-40 pitch temperature becomes much more pronounced when bread yeast and modern brewers yeast is taken out. (This figure also excludes those brewers of whom we cannot be sure whether they had their own yeast or not.)

As can be seen in Figure 4 there is less data on the brewers who have their own yeast, but the dominance of $35-40{ }^{\circ} \mathrm{C}$ is clearly stronger (up from $53 \%$ of all accounts to $60 \%$ ), and the geographic pattern still holds, although for Estonia it's now relatively weak. (The Estonian survey answers from ERM are mostly very brief, and say very little about the yeast, so that for most of them it's not possible to say with certainty whether the brewers had their own yeast or not.)

Many of the accounts used in this paper are from brewers who use or used kveik, which is famous for handling high temperatures. Recent studies show that these yeasts can ferment very warm without producing fusel alcohols or other off flavours (2).

However, the farmhouse yeasts that have been collected from Latvia, Lithuania, and Russia do not belong to the kveik family. The same goes for Belgian saison yeast. They still handle high temperatures. Most likely the farmhouse yeasts of Sweden, Denmark, Finland, and Estonia were not kveik, either. In short, it seems that the ability to ferment at high temperatures without producing off flavours was common to most types of farmhouse yeasts.

\section{Fermentation temperature}

The pitch temperature is the temperature of the wort as the yeast is added to it, but this of course need not be the fermentation temperature. And of course, for the flavour of the beer, the fermentation temperature is what matters. 
Most of these brewers ferment large batches of 100-150 litres, and they usually insulate their fermentors, which means that the temperature can rise during fermentation. Sigmund Gjernes in Voss, Norway pitches at $39^{\circ} \mathrm{C}$, but has measured the temperature during fermentation to $43^{\circ} \mathrm{C}$. Sjur Rørlien, also in Voss, pitches at $40{ }^{\circ} \mathrm{C}$, and sent the author a video of his beer fermenting at $45^{\circ} \mathrm{C}$. Terje Raftevold in Hornindal, Norway pitches his yeast at $30{ }^{\circ} \mathrm{C}$, but at the height of fermentation the author measured the fermenting beer to $32.6{ }^{\circ} \mathrm{C}$.

Historically, at least in Norway and Sweden, it was extremely common to pack cloths, blankets, or pelts around the fermentor to ensure that the wort stayed warm. Many also placed the fermentor in a heated room to ensure that it would remain warm enough.

There is every reason to believe that fermentation temperatures were at least as high as the pitch temperature, and probably in most cases higher.

\section{Chronology}

The sources in this study were mostly recorded in the period 1930 to 1955, and for the most part describe the period 1880 to 1950 . Very likely the temperatures were the same in earlier times as well, since the farmhouse yeast cultures were able to handle these temperatures. This is supported by the few older historical sources that discuss the subject. (These historical sources are not included in the survey above, since they do not describe the brewing tradition in any specific location.)

Anna Wecker's Danish cookbook from 1616 (9) contains a beer recipe where the pitch temperature is described as "milkwarm".

Carl Niclas Hellenius's treatise on Finnish farmhouse brewing from 1780 (10) says when sticking a finger in the wort the wort should feel lukewarm around the finger (probably body temperature), but it should feel like there is a cold ring round the finger at the surface. He is very likely describing a temperature a few degrees below body temperature.

Linnaeus's treatise on beer from 1749 (11) recommends the same temperature.

John Christian Molbech's treatise on farmhouse brewing from 1796 (12) says the pitch temperature should be between 20 and 28 degrees Réaumur, which translates to $25-35 \mathrm{C}$.

Niels Prahl's book on good housekeeping practice from 1778 (13) specifies the temperature as "milkwarm". 
Many more examples could be given. In short, it seems that in the 17th and 18th centuries pitch temperatures in Scandinavia followed the same general pattern that the farmhouse brewing accounts describe.

Ronald Pattinson has a very large collection of brewing records from commercial British breweries. He says: "The oldest logs I have, from just after 1800, list fermentation temperatures. Most beers were pitched around $16^{\circ} \mathrm{C}$ but could rise to as high as $28^{\circ} \mathrm{C}$ for beers like Porter." In short, if commercial breweries in earlier times also used high fermentation temperatures it was long ago.

\section{Discussion}

It's clear that farmhouse brewers in the Nordic and Baltic countries fermented at high temperatures. It seems likely that the same was the case in the rest of the northern European farmhouse brewing regions, including the UK and Russia.

Since this practice will have given poor results with the type of yeast that is used in modern commercial brewing it's clear that these brewers must have used other types of yeast. And, indeed, all of the surviving farmhouse yeasts that have been analysed prove to be of kinds different from modern commercial yeast.

Yet these farmhouse yeasts are not a single type of yeast, genetically speaking. The kveik family of farmhouse yeasts from western Norway belongs to Beer 1 (2), while the saison yeasts of Belgium belong to Beer 2. (Saison brewers have not been included in this survey, because of a lack of sources that fit the criteria for inclusion, but are also famous for fermenting unusually warm by modern standards.) Unpublished analyses indicate that the Lithuanian, Latvian, and Russian farmhouse yeasts do not belong to either Beer 1 or Beer 2.

Yet all of these yeasts show clear signs of domestication. This is particularly well established for the kveik family (2).

What is intriguing is that modern baking yeast also clearly handles high fermentation temperatures, at least in most cases, as shown by data from modern farmhouse brewers in Norway, Sweden, Finland, Estonia, Lithuania, and Russia.

In short, tolerance of high fermentation temperatures appears to have been (and still be) a shared trait across a very wide range of yeast types. There are also indications that wild yeast naturally has higher temperature tolerance than modern commercial yeast (14). Indeed, it begins to seem 
as if it is modern commercial brewer's yeast that is anomalous in lacking the ability to tolerate high temperatures.

Farmhouse brewing is clearly far older than modern commercial brewing, and so it seems likely that high-temperature brewing came first. If wild yeast really has higher temperature tolerance to begin with, this would explain why farmhouse brewers could ferment warm despite the wide range of yeasts they used. If the yeast already had this ability in nature there was no need to introduce it through domestication, which would have involved a difficult evolutionary path where fermentation would have had to first happen at lower temperatures, then gradually push higher as the yeast evolved to tolerate it.

High fermentation temperatures are so dominant in farmhouse brewing that it seems likely they reflect fundamental technical aspects. Historically farmhouse brewers did not have equipment for cooling their wort. With typical batch sizes of 100-150 litres, generally being left to cool in wooden fermentors, cooling was slow business, as shown by the archive accounts. In many cases, the brewer had been busy since early morning, and was waiting impatiently for the wort to cool so the yeast could be pitched and they could go to bed.

Further, the longer the brewer had to wait before the yeast could be pitched, the more time undesirable microbes had to get established, before the brewer's yeast could begin to multiply and reshape the environment to suit itself.

The closer the temperature of the wort gets to the ambient temperature, the slower it cools. So while cooling from $100 \mathrm{C}$ ( or $65 \mathrm{C}$ ) to $40 \mathrm{C}$ will have taken a good while, cooling even further to 20C would take disproportionately longer.

In short, farmhouse brewers had every reason to prefer to pitch the yeast as soon as possible, and it's clear they did. This is most likely the driver for the surprisingly uniform high fermentation temperatures.

Commercial brewers, however, quite early had access to cooling technology such as coolships. They may have discovered that lactic acid bacteria and other infectants are disadvantaged by cooler fermentation (around 20C). Preferring these temperatures is then likely to have gradually pushed the pitch temperature down.

Eventually, once low (15-20C) fermentation temperatures had become the norm, it's likely that the brewer's yeast will have lost its ability to tolerate the high temperatures. Loss-of-function is likely to happen in yeast when it no longer needs a specific function (15), for the simple reason that degenerative mutations no longer incur any evolutionary penalty. 
Thus it seems that the stark differences in pitch temperatures between farmhouse and commercial brewing represent their different technological circumstances. The two types of brewers found that different strategies were optimal for avoiding sour beer, and so adopted different brewing methods. Over time, the yeast adapted accordingly.

It seems likely that commercial heat-intolerant yeast developed out of farmhouse yeast together with commercial brewing. In this context, the lager brewers of southern Germany and Bohemia most likely were part of the same development, but lowered their pitch temperatures even lower because a happy accident of genetics (the formation of lager yeast through a chance hybridisation) allowed them to do so.

Admittedly, much of this reasoning cannot be conclusively proved (nor disproved) from the state of current research. It is to be hoped that further work on the genetic history of brewer's yeast can finally settle the issue.

\section{Acknowledgements}

The author is grateful for valuable feedback on the manuscript from Richard Preiss and Edward Wray. He is also grateful to a large number of people for help in gathering the data, but they are far too many to thank here.

\section{Conflict of interest}

The author declares there are no conflicts of interest.

\section{References}

(1) Garshol LM. 2020. Historical brewing techniques: the lost art of farmhouse brewing. Brewers Publications, Boulder, USA.

(2) Preiss R, Tyrawa C, Krogerus K, Garshol LM, van der Merwe G. 2018. Traditional Norwegian Kveik are a Genetically Distinct Group of Domesticated Saccharomyces cerevisiae Brewing Yeasts. Frontiers in Microbiology, Evolutionary and Genomic Microbiology, 12 September 2018. doi.org/10.3389/fmicb.2018.02137

(3) NEG 7329. Norsk Etnologisk Granskning, Oslo, Norway. Questionnaire 35, response 7329. 
(4) Nordal, A. Jofolket: ein slekts- og miljøstudie frå ein Vestlandsdal frå tida 1835-1985. Selfpublished.

(5) NEG 14060.

(6) NEG 9392.

(7) NEG 7325.

(8) Laitinen, M. 2019. Viking Age Brew: The Craft of Brewing Sahti Farmhouse Ale. Chicago Review Press, Chicago, USA.

(9) Wecker A. 1616. Koge Bog, indeholdendis et hundrede fornødene Stycker. Copenhagen, Denmark.

(10) Hellenius CN. 1780. Anmärkningar öfver finska allmogens bryggningssätt. Åbo Academy, Turku, Finland.

(11) von Linné C. 1749. Beskrifning om Öl. In Almanach för året 1749. Svensk Vetenskapsakademi, Stockholm, Sweden.

(12) Molbech JC. 1796. Afhandling om Ølbrygningen i sin fulde Udstrækning. Gyldendal, Copenhagen, Denmark.

(13) Prahl N. 1778. Den oeconomiske haand-bog, bind 2. Copenhagen, Denmark.

(14) Peter J et al. 2018. Genome evolution across 1,011 Saccharomyces cerevisiae isolates. Nature volume 556, pages 339-344.

(15) Lancaster SM, Payen C, Smukowski Heil C, Dunham MJ. 2019. Fitness benefits of loss of heterozygosity in Saccharomyces hybrids. Genome Research, 2019. 29: 1685-1692.

\section{Tables and figures}


Table 1: The archive sources.

Prefix Institution

AFD Afdeling for Dialektforskning, Copenhagen University 64

ERM Estonian National Museum 276

EU Etnologiska Undersökningen, Nordic Museum 216

KM Finnish National Museum 23

LUF Lunds Universitet, Folkminnesarkiv 26

NEG Norsk Etnologisk Granskning 182

NEU Nationalmuseets Etnologiske Undersøgelser 104

SLS Svenska Litteratursällskapet $\quad 35$

SM Šiauliai Aušros Museum, Lithuania 8

VOKO Volkskundliche Kommission für Westfalen 11

Table 2: The various temperature descriptions, their interpretation, and the number of accounts that specify each.

\section{Description Temperature Accounts}

Single number Varies $\quad 130$

Numeric range $\quad$ Varies $\quad 41$

Body temperature $\quad 37 \quad 35$

$\begin{array}{lll}\text { Milkwarm } & 36 & 84\end{array}$

Uninterpretable None $\quad 55$

Figure 1: Histogram of all the temperatures.

\section{Accounts}

3

6


Pitch temperatures

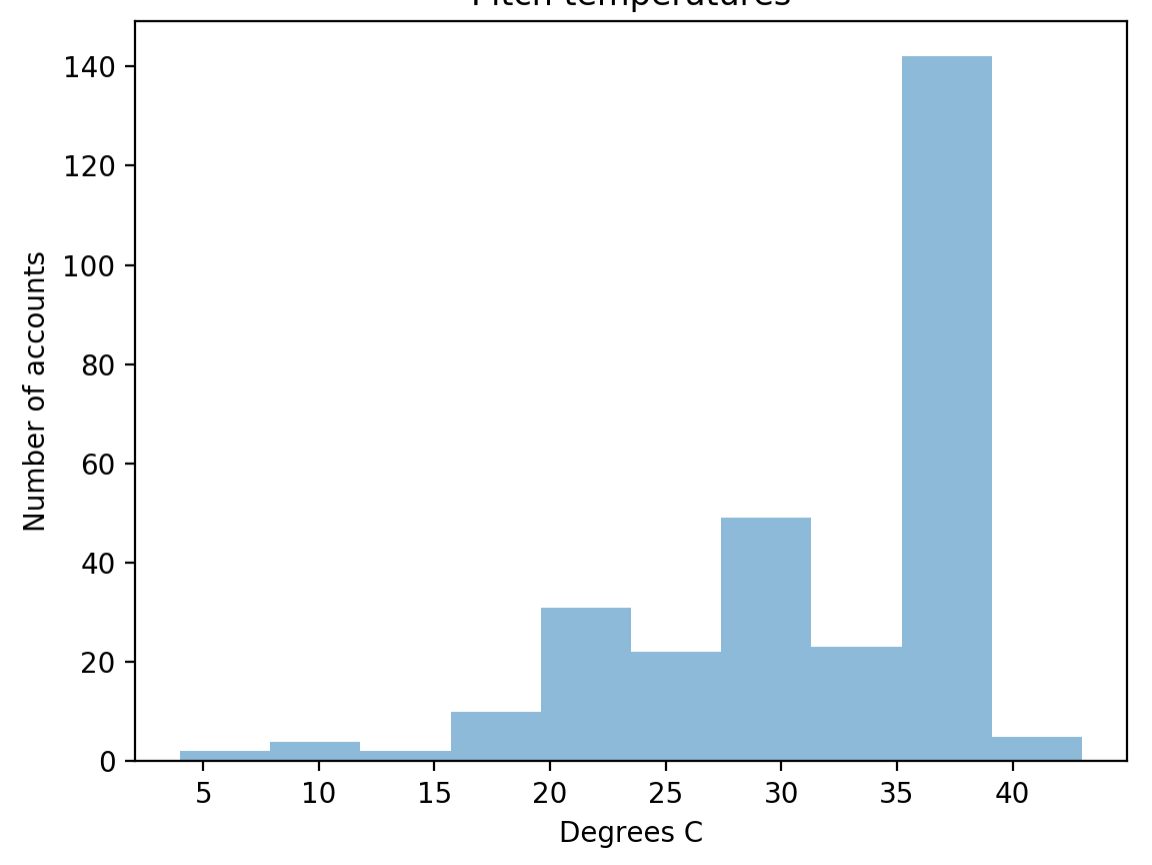


Figure 2: Number of temperatures by country and by 5-degree interval. In each interval the low number is inclusive and the high number exclusive.

\begin{tabular}{|c|c|c|c|c|c|c|c|c|c|c|}
\hline Country & $0-5$ & $5-10$ & $10-15$ & $15-20$ & $20-25$ & 25-30 & 30-35 & $35-40$ & $40-45$ & Accounts \\
\hline Norway & $0 \%$ & $0 \%$ & $0 \%$ & $2 \%$ & $5 \%$ & $10 \%$ & $16 \%$ & $62 \%$ & $4 \%$ & 154 \\
\hline Denmark & $0 \%$ & $0 \%$ & $0 \%$ & $10 \%$ & $32 \%$ & $15 \%$ & $7 \%$ & $37 \%$ & $0 \%$ & 41 \\
\hline Sweden & $0 \%$ & $0 \%$ & $0 \%$ & $6 \%$ & $6 \%$ & $19 \%$ & $13 \%$ & $56 \%$ & $0 \%$ & 32 \\
\hline Estonia & $0 \%$ & $0 \%$ & $0 \%$ & $4 \%$ & $19 \%$ & $26 \%$ & $7 \%$ & $44 \%$ & $0 \%$ & 27 \\
\hline Finland & $14 \%$ & $0 \%$ & $14 \%$ & $7 \%$ & $43 \%$ & $7 \%$ & $7 \%$ & $7 \%$ & $0 \%$ & 14 \\
\hline Lithuania & $0 \%$ & $0 \%$ & $0 \%$ & $0 \%$ & $20 \%$ & $20 \%$ & $40 \%$ & $20 \%$ & $0 \%$ & 5 \\
\hline Russia & $0 \%$ & $0 \%$ & $0 \%$ & $0 \%$ & $25 \%$ & $0 \%$ & $25 \%$ & $50 \%$ & $0 \%$ & 4 \\
\hline UK & $0 \%$ & $0 \%$ & $0 \%$ & $0 \%$ & $0 \%$ & $0 \%$ & $0 \%$ & $100 \%$ & $0 \%$ & 4 \\
\hline Germany & $0 \%$ & $33 \%$ & $0 \%$ & $33 \%$ & $0 \%$ & $33 \%$ & $0 \%$ & $0 \%$ & $0 \%$ & 3 \\
\hline Latvia & $0 \%$ & $0 \%$ & $0 \%$ & $0 \%$ & $0 \%$ & $50 \%$ & $50 \%$ & $0 \%$ & $0 \%$ & 2 \\
\hline Georgia & $0 \%$ & $0 \%$ & $0 \%$ & $0 \%$ & $100 \%$ & $0 \%$ & $0 \%$ & $0 \%$ & $0 \%$ & 1 \\
\hline Total & 2 & 1 & 2 & 12 & 37 & 39 & 39 & 149 & 6 & 287 \\
\hline Percent & $1 \%$ & $0 \%$ & $1 \%$ & $4 \%$ & $13 \%$ & $14 \%$ & $14 \%$ & $52 \%$ & $2 \%$ & $100 \%$ \\
\hline
\end{tabular}

The same data as a table without colours, for the print version 
Country 0-5 5-10 10-15 $15-20 \quad 20-25 \quad 25-30$ 30-35 35-40 40-45 Accounts

$\begin{array}{llllllllllll}\text { Norway } & 0 \% & 0 \% & 0 \% & 2 \% & 5 \% & 10 \% & 16 \% & 62 \% & 4 \% & 154\end{array}$

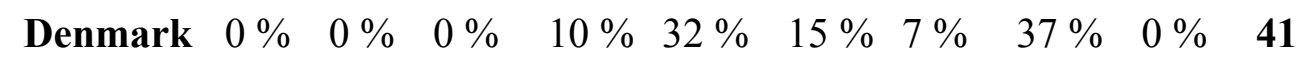

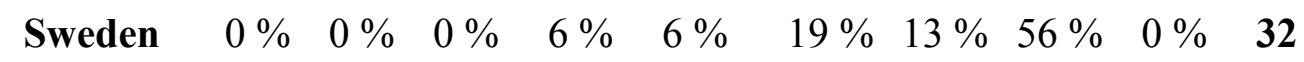

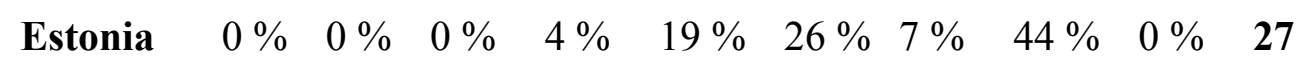

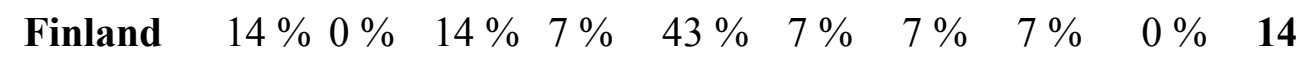

$\begin{array}{lllllllllllllll}\text { Lithuania } & 0 \% & 0 \% & 0 \% & 0 \% & 20 \% & 20 \% & 40 \% & 20 \% & 0 \% & 5\end{array}$

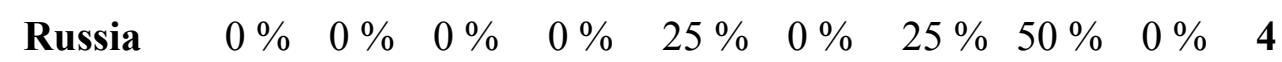

UK $\quad \begin{array}{lllllllllllll}0 \% & 0 \% & 0 \% & 0 \% & 0 \% & 0 \% & 0 \% & 100 \% & 0 \% & 4\end{array}$

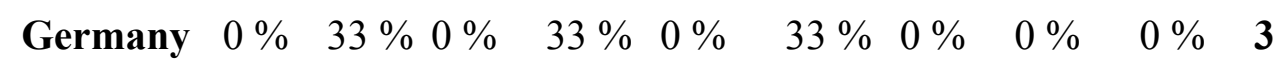

Latvia $\quad \begin{array}{lllllllllllll} & 0 \% & 0 \% & 0 \% & 0 \% & 0 \% & 50 \% & 50 \% & 0 \% & 0 \% & 2\end{array}$

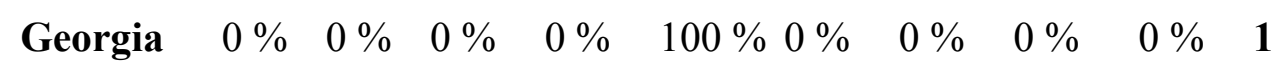

$\begin{array}{lllllllllll}\text { Total } & 2 & 1 & 2 & 12 & 37 & 39 & 39 & 149 & 6 & 287\end{array}$

$\begin{array}{lllllllllllll}\text { Percent } & 1 \% & 0 & 0 & 1 \% & 4 \% & 13 \% & 14 \% & 14 \% & 52 \% & 2 \% & 100 & 0\end{array}$

Figure 3: Histogram only for brewers who have their own yeast. 


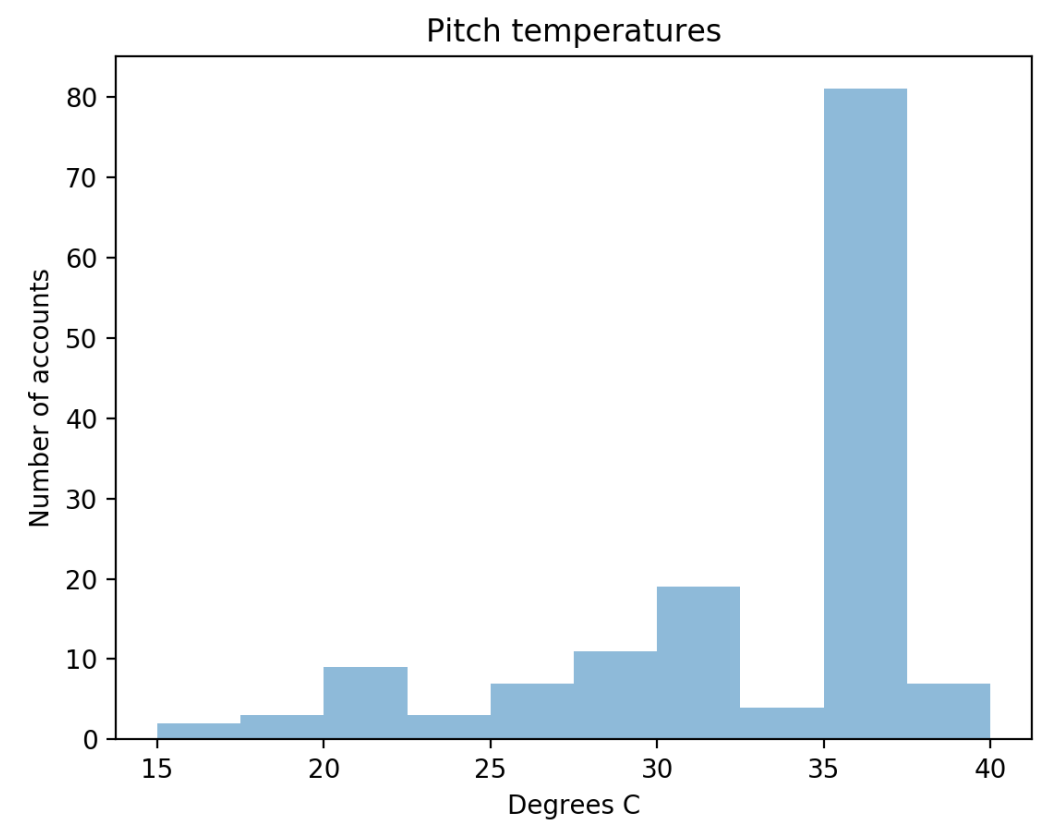

Figure 4: Number of temperatures by country and by 5-degree interval for brewers who have their own yeast. 
Country 15-20 20-25 25-30 30-35 35-40 40-45 Accounts

$\begin{array}{lllllllll}\text { Norway } & 2 \% & 3 \% & 9 \% & 18 \% & 63 \% & 3 \% & \mathbf{8 7}\end{array}$

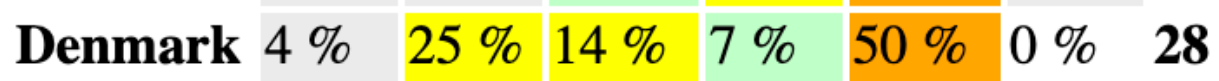

$\begin{array}{lllllllll}\text { Sweden } & 7 \% & 7 \% & 20 \% & 7 \% & 60 \% & 0 \% & \mathbf{1 5}\end{array}$

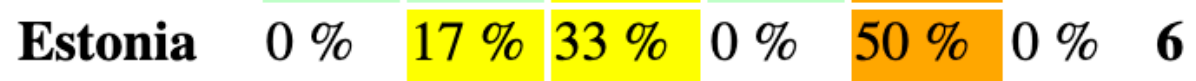

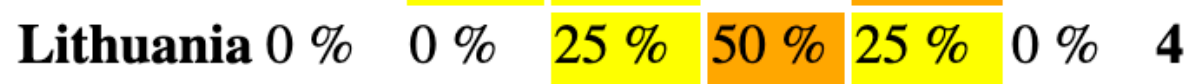

$\begin{array}{lllllllll}\text { Russia } & 0 \% & 50 \% & 0 \% & 0 \% & 50 \% & 0 \% & \mathbf{2}\end{array}$

UK $\quad \begin{array}{lllllllll}0 \% & 0 \% & 0 \% & 0 \% & 100 \% & 0 \% & \mathbf{2}\end{array}$

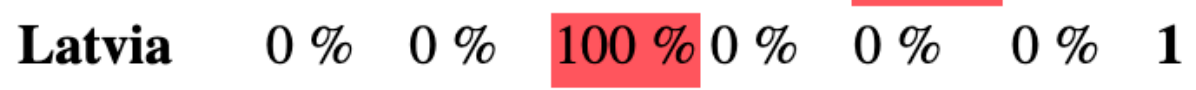

$\begin{array}{llllllll}\text { Total } & 4 & 13 & 19 & 21 & 85 & 3 & 145\end{array}$

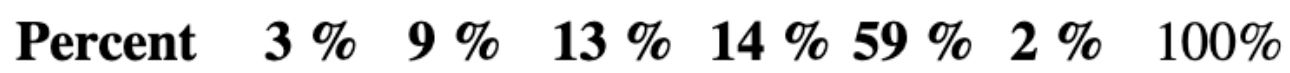


Black-and-white version of the same table.

$\begin{array}{llllllll}\text { Country } & \mathbf{1 5 - 2 0} & \mathbf{2 0 - 2 5} & \mathbf{2 5 - 3 0} & \mathbf{3 0 - 3 5} & \mathbf{3 5 - 4 0} & \mathbf{4 0 - 4 5} & \text { Accounts } \\ \text { Norway } & 2 \% & 3 \% & 9 \% & 18 \% & 63 \% & 3 \% & \mathbf{8 7} \\ \text { Denmark } & 4 \% & 25 \% & 14 \% & 7 \% & 50 \% & 0 \% & \mathbf{2 8} \\ \text { Sweden } & 7 \% & 7 \% & 20 \% & 7 \% & 60 \% & 0 \% & \mathbf{1 5} \\ \text { Estonia } & 0 \% & 17 \% & 33 \% & 0 \% & 50 \% & 0 \% & \mathbf{6} \\ \text { Lithuania } & 0 \% & 0 \% & 25 \% & 50 \% & 25 \% & 0 \% & \mathbf{4} \\ \text { Russia } & 0 \% & 50 \% & 0 \% & 0 \% & 50 \% & 0 \% & \mathbf{2} \\ \text { UK } & 0 \% & 0 \% & 0 \% & 0 \% & 100 \% & 0 \% & \mathbf{2} \\ \text { Latvia } & 0 \% & 0 \% & 100 \% & 0 \% & 0 \% & 0 \% & \mathbf{1} \\ \text { Total } & \mathbf{4} & \mathbf{1 3} & \mathbf{1 9} & \mathbf{2 1} & \mathbf{8 5} & \mathbf{3} & \mathbf{1 4 5} \\ \text { Percent } & \mathbf{3 \%} & \mathbf{9 \%} & \mathbf{1 3} \% & \mathbf{1 4} \% & \mathbf{5 9} \% & \mathbf{2} \% & \mathbf{1 0 0} \%\end{array}$

Figure 5: Pitch temperatures by location. 


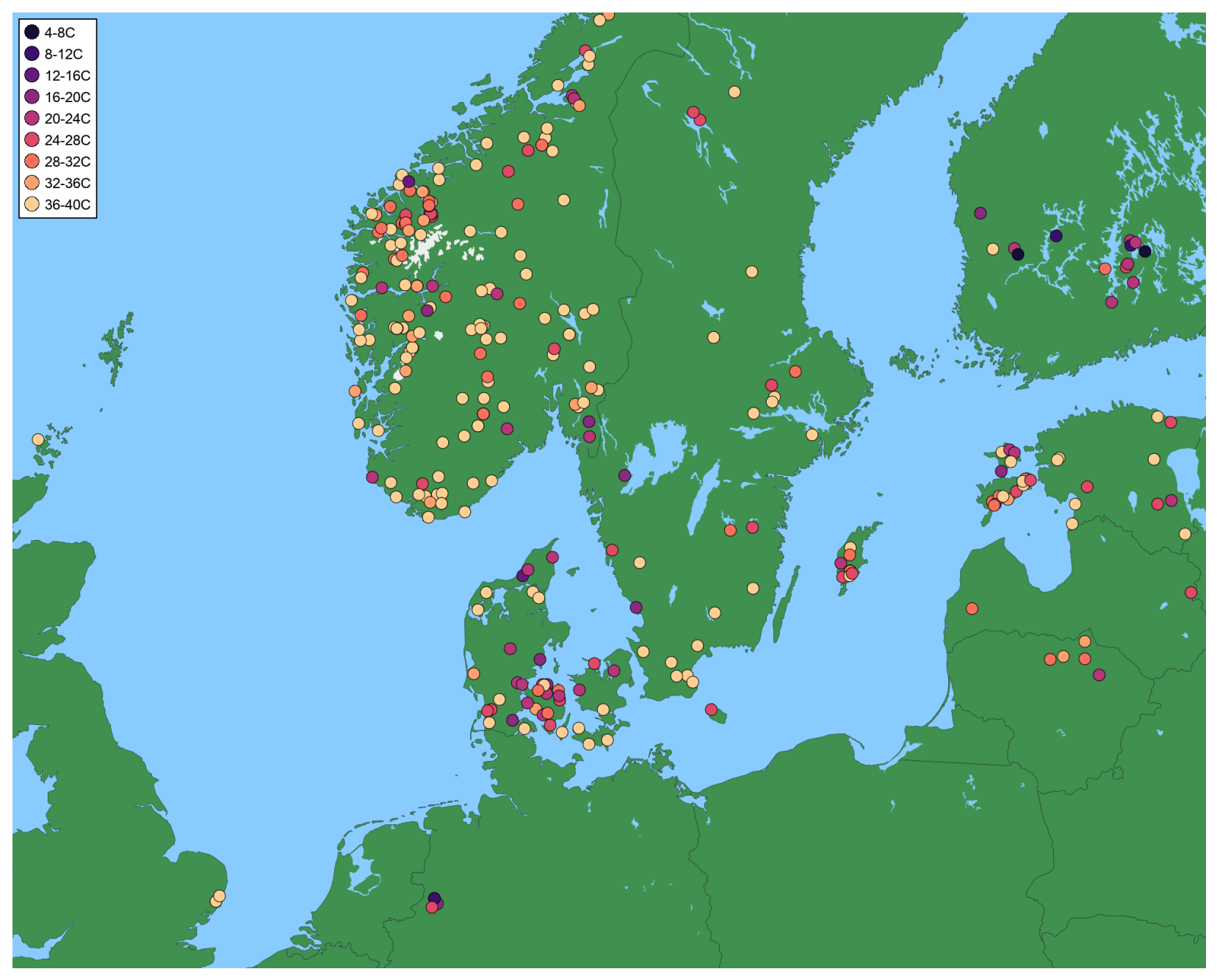


Black-and-white version of same:

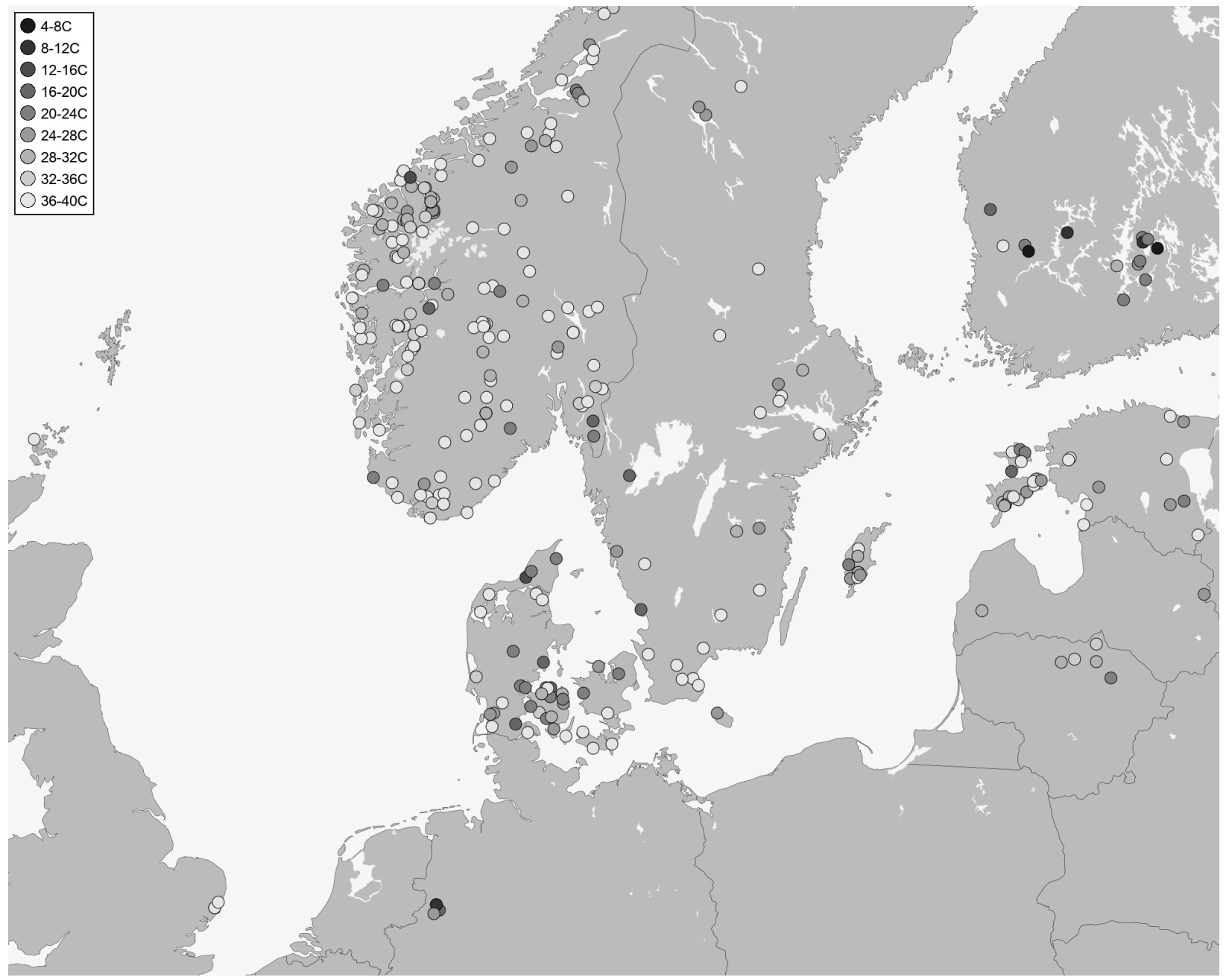

